\title{
AVALIAÇÃO DA APRENDIZAGEM: QUAL O SIGNIFICADO EM SALA DE AULA?
}

\author{
Cláudia Fátima de Melo Favarão ${ }^{1}$ \\ Rosana Figueiredo Salvi ${ }^{2}$
}

\section{RESUMO}

As conversas referentes ao processo de avaliação da aprendizagem, nas escolas estaduais nas quais atuo como professora de Geografia sempre gerou inquietação. Os questionamentos levantados na experiência vivida levaram a construção teórica de uma dissertação a respeito da concepção dos professores dos anos finais do ensino fundamental sobre o processo de avaliação da aprendizagem. As dúvidas e incertezas construíram e reconstruíram nossa formação pedagógica, provocando novas problematizações que reverberaram nas seguintes questões: - Compreendo o que significa avaliar? - Os conceitos geográficos estão sendo ensinados e aprendidos? Como? - Qual o tipo de avaliação que realizo em sala de aula? - Será que a avaliação chamada de classificatória ainda persiste nas salas de aula? - Por quê? - Qual o significado da Avaliação Classificatória e de avaliação Formativa? - A avaliação formativa é colocada em prática? Os erros estão sendo considerados nas aulas de Geografia como parte do processo de construção da aprendizagem? Os resultados apontam o difícil percurso para a construção de uma avaliação voltada para a formação humana.

Palavras - chave: Avaliação. Classificatória. Formativa.

A disposição de acolher está no sujeito do avaliador, e não no objeto da avaliação. $\mathrm{O}$ avaliador é o adulto da relação de avaliação, por isso ele deve possuir a disposição de acolher. Ele é o detentor dessa disposição. E, sem ela, não há avaliação. Não é possível avaliar um objeto, uma pessoa ou uma ação, caso ela seja recusada ou excluída, desde o início, ou mesmo julgada previamente. Que mais se pode fazer com um objeto, ação ou pessoa que foram recusados, desde o primeiro momento? Nada, com certeza!

Cipriano Carlos $\quad 2000$

\footnotetext{
${ }^{1}$ Doutoranda do Programa de Pós-graduação em Geografia na Universidade Estadual de Londrina. Resultado da Dissertação do Mestrado em Educação: Avaliação da Aprendizagem: concepções e características (2012).

2 Doutora em Geografia, professora do Departamento de Geografia UEL e Coordenadora do Grupo de Estudos GEMPEA (Grupo de Estudos Multidisciplinar dos Processos de Ensino e Aprendizagem)
} 


\section{SEMINÁRIO DE PESQUISA EM CIÊNCIAS HUMANAS - SEPECH \\ Humanidades, Estado e desafios didático-científicos \\ Londrina, 27 a 29 de julho de 2016}

A sala de aula é lugar de inúmeras histórias, de ensinar e de aprender, em que professores e estudantes são criações e criadores. Histórias de amor, tristeza, alegria, de vida e de 'saberes e não saberes', (ESTEBAN, 1992) que, muitas vezes são desconsiderados no espaço escolar. Dentre as histórias tristes, há o medo do 'dia da prova', o medo de tirar nota baixa. Esse sentimento de tristeza ronda os pensamentos dos estudantes, pois tal anseio ocorre pelo fato de professores, diretores e pedagogos acreditarem que para manter os estudantes 'na linha' e para tirar 'nota boa', a utilização do medo é fundamental para o sucesso da aprendizagem.

O medo, conforme Luckesi (2011, p. 42),

[...] é um fator importante no processo de controle social. Internalizado, é um excelente freio às ações que são supostamente indesejáveis. Daí, o Estado, a Igreja, a família e a escola utilizarem-se dele de forma exacerbada. O medo gera a submissão forçada e habitua a criança e o jovem a viverem sob sua égide. [...] Produz não só uma personalidade submissa como também hábitos de comportamento físico tenso que conduzem às doenças $[. .$.$] .$

As histórias criadas dentro da sala de aula, ao trazerem à memória, sentimentos desagradáveis, são referentes ao caráter classificatório da avaliação da aprendizagem. Nesse processo, sobressaem as lembranças de sofrimento, ora por não se ter aprendido, ora por não conseguir o resultado esperado na prova, porque fracassou ou também por não ter tido a oportunidade de expressar o "não saber." (ESTEBAN, 1992). Esse fato ocorre, similarmente, por exposições constrangedoras do corpo do aluno, seus valores, imagem e de história de vida.

Ainda que a sala de aula seja constituída pelo movimento, pela surpresa, pela turbulência, pela desordem, pela diferença, as práticas escolares e os processos ensino/aprendizagem estão estruturados para conduzir à homogeneidade, à convergência, à linearidade, considerados essenciais para uma boa relação pedagógica. (ESTEBAN, s/d, p. 4)

Essa ideia de avaliação classificatória tem por preocupação a constatação de resultados para a produção de notas, que se embasarão em médias e as decisões de aprovação ou não. Assim, essas ações pouco contribuem para que o professor(a) promova ajustes no processo de ensino, no intuito de gerar condições para que o estudante construa sua aprendizagem.

Ao possibilitar a simples ação constatatória, avalia-se para verificar o que foi ou não retido, mas não se enuncia qualquer preocupação com a retomada das dificuldades para a construção da aprendizagem. Essa é uma das características centrais de uma avaliação exercida para a classificação, classificar aqueles que 'sabem', daqueles que 'ainda não sabem'. (ESTEBAN, 1992) Para Luckesi (2011, p. 190), “[...] o estudante é tomado exclusivamente como um sujeito que responde a um instrumento de coleta de dados [...] ou participa de uma atividade; e, aconteça o que acontecer, ele é o único responsável." Delegar a responsabilidade somente no estudante é o papel fundamental da avaliação chamada classificatória. Isso, no entanto, não quer dizer que o estudante não deva ter responsabilidade por seus estudos. 


\section{SEMINÁRIO DE PESQUISA EM CIÊNCIAS HUMANAS - SEPECH \\ Humanidades, Estado e desafios didático-científicos \\ Londrina, 27 a 29 de julho de 2016}

Toda e qualquer atividade avaliativa - independentemente de resultar ou não em nota - é importante no contexto da sala de aula. Por isso, quando o professor almeja dispor de indicadores que the favoreçam promover situações promotoras de aprendizagem, ele precisa dar mais atenção às situações de ensino. Porém, alguns creem que o resultado alcançado pelo estudante é decorrente, exclusivamente, de seu empenho. Luckesi (2011, p. 428) complementa que a reprovação "[...] constitui um fenômeno que historicamente tem a ver com a ideologia segundo a qual, se o estudante não aprende, seu insucesso é exclusivamente responsabilidade sua ou, [...] é decorrência de seu descuido ou má vontade."

A cultura da seleção e da exclusão, (LOPES, 2006; LUCKESI, 2003, 2005, 2011; SANTOS GUERRA, 2007; dentre outros), existente nas escolas, é fortalecida, a cada ano por professores, pais e sociedade, na crença de que a melhor atitude a ser tomada com estudantes, por mostrarem um mau comportamento e por revelarem parco domínio dos conhecimentos transmitidos, é a reprovação.

A reprovação gera nos estudantes sentimentos de incapacidade para aprender. Essa incapacidade reside neles e, por isso, culpam-se por fracassar, autoexcluem-se e, geralmente, abandonam a escola. Todavia, a decorrência da avaliação, quando empreendida para diagnosticar as dificuldades de aprendizagem, muito mais do que para subtrair pontos pelo erro cometido, deveria ser a promoção da aprendizagem. Segundo Luckesi (2011, p. 429), “[...] oferecer ensino a educandos e reprová-los são atos contraditórios. Quem ensina tem como objetivo o aprendizado do outro. A reprovação aborta o ato de ensinar e de aprender."

O estudante precisa dominar o conteúdo ministrado pelo professor e ter responsabilidade por seus estudos. No entanto, é imprescindível que suas dificuldades de aprendizagem sejam detectadas e solucionadas com o auxílio do professor, a quem compete conceber diferentes estratégias de ensino e, ao mesmo tempo, municiar o estudante com novas estratégias de aprendizagem. Por isso, conforme Esteban (s/d, p. 7, destaque nosso), "na avaliação educacional, um dos aspectos centrais é a atribuição de 'valor positivo' ao saber e 'negativo' ao não saber. Tendo o objetivo de distinguir os que sabem dos que não sabem [...]".

Tal comportamento de busca incessante por meros resultados perpetua a seletividade, a exclusão, o individualismo, sem gerar preocupações com a aprendizagem. De acordo com Santos Guerra (2007, p. 49, destaque do autor), "[...] o êxito é alcançado quando se obtém aprovação, não quando se aprende. Um estudante diz que perdeu o ano quando não é aprovado. Caso consiga uma excelente qualificação, pouco importa o que foi aprendido."

Por viver nesse modelo hierárquico instalado em sala, cada vez mais, o estudante que apresenta dificuldades, desacredita de sua capacidade para aprender. Os momentos da exposição das notas e do enaltecimento dos melhores sempre funcionam como tortura, subjugando aqueles com dificuldades. E, ainda, amplia o poder do professor e fortifica a competição. Consoante Zanatto (2007, p. 44, destaque do autor),

elogiar publicamente um aluno que tirou a melhor nota na prova, bem como apresentá-lo como referência a ser seguida pela turma [...] pode levar para os estudantes 'mais fracos' a mensagem de que não importa seu esforço nunca atingirão a meta imposta pelo professor. 


\section{SEMINÁRIO DE PESQUISA EM CIÊNCIAS HUMANAS - SEPECH \\ Humanidades, Estado e desafios didático-científicos \\ Londrina, 27 a 29 de julho de 2016}

Diante das respostas dos estudantes em sala de aula, é preciso, de certa forma, tomar uma decisão que permita o estudante ultrapassar, caminhar em construção de seus conhecimentos porque não se neutraliza com a identificação do erro ou do acerto, não busca relações sem significado entre o que é observável e os processos que o atravessam. Indaga o que se faz visível e procura pistas do que é conduzido à invisibilidade. (ESTEBAN, s/d).

A sala de aula, desse modo, torna-se homogênea no momento em que os professores acreditam que todos os estudantes aprendam, linearmente e que a exposição da aula atingirá a todos. Qual decisão tomar? Qual processo de avaliação da aprendizagem concretizar em sala de aula? $\mathrm{O}$ que uma avaliação classificatória produz no processo de aprendizagem? E na formação humana? E a formativa? Os erros estão sendo considerados nas aulas de Geografia como parte do processo de construção da aprendizagem? E a construção de uma avaliação voltada para a formação humana? Está acontecendo?

A reflexão a respeito do processo de avaliação da aprendizagem em Geografia, em Matemática, em Arte, e nas demais disciplinas do Ensino Fundamental, anos finais, está acontecendo, porém lentamente.

Avaliação formativa é aquela comprometida com o levantamento de informações acerca do processo de aprendizagem vivenciado pelo estudante, mas para além do diagnóstico, os dados advindos de seu exercício subsidiam as reflexões docentes para a intuito de lhes facultar a elaboração, implementação de ações didáticas favoráveis à superação dos problemas e à compreensão das dificuldades de aprendizagem.

\section{UM OLHAR MAIS ATENCIOSO PARA O ATO DE AVALIAR}

Avaliar, formativamente, é aceitar o desafio e o compromisso de realizar um percurso em conjunto - porque solidário entre quem ensina e quem aprende -, o que demanda paradas e ajudas, estendendo a mão para oferecer apoio. Por isso mesmo, conforme Perrenoud (1999, p. 103, destaque do autor), "é formativa toda avaliação que ajuda o aluno a aprender e a se desenvolver, ou melhor, que participa da regulação das aprendizagens e do desenvolvimento no sentido de um projeto educativo."

O objetivo da ação do professor, nesta perspectiva de avaliação, é ajudar o estudante a construir degraus na elaboração e construção de conceitos, sem padronizar e comparar, pois lhe cumpre compreender a diversidade de aprendizagens presente em sala de aula para poder, em consequência, abordá-las de forma pertinente e oportuna. Para Hadji (2001, p. 15), "[...] deve se pôr a avaliação a serviço das aprendizagens o máximo possível."

De acordo Hoffmann (2001, p. 21), a avaliação da aprendizagem não "[...] tem por objetivo a verificação e o registro de dados do desempenho escolar, mas a observação permanente das manifestações de aprendizagem para proceder a uma ação educativa que otimize percursos individuais." Assim, o compromisso não é a limitação do que já foi, mas as possibilidades que se oferecem quando a intenção maior é investigar, esclarecer e entender para organizar experiências significativas de aprendizagem.

A realização da avaliação formativa procura compreender que todos os sentidos 


\section{SEMINÁRIO DE PESQUISA EM CIÊNCIAS HUMANAS - SEPECH \\ Humanidades, Estado e desafios didático-científicos \\ Londrina, 27 a 29 de julho de 2016}

devem conectar-se com a sala de aula. Não é um simples ver, ouvir, falar e sentir, mas uma observação atenta e com objetivos claros, que leva a um agir propiciador de superação das dificuldades de aprendizagem. Teixeira e Nunes (2008, p. 104), ao alargar e multiplicar a compreensão dos percursos de aprendizagem, o professor [toma para si] que "[...] avaliar é saber conhecer o que cada aluno consegue e saber exigir o que cada um é capaz de dar, compelindo outras ações além dessas."

Para Álvarez Méndez (2002, p. 14), a avaliação “[...] deve ser entendida como atividade crítica de aprendizagem, porque se assume que a avaliação é aprendizagem no sentido de que por meio dela adquirimos conhecimentos." Professores aprendem com o que as respostas dos alunos revelam. Eles compreendem o que os alunos ainda não sabem e, em consequência, podem aperfeiçoar sua prática docente e colaborar para as aprendizagens. Também, os alunos assimilam principalmente quando lhes são oferecidos espaços para o questionamento e para a contra-argumentação em face dos próprios erros.

A avaliação, em seu exercício formativo, não se limita ao diagnóstico, mas orienta o planejamento e intervenção, que pretendem favorecer a promoção da aprendizagem - o que nada mais é que conceber, elaborar e implementar feedbacks.

Para diagnosticar as aprendizagens, realizadas ou em curso, é fundamental estabelecer um paralelo entre os objetivos traçados e as informações coletadas por meio do instrumental avaliativo. Por isso, o levantamento de informações, no processo de avaliação formativa, deve ser orientado pelos objetivos firmados no plano de ensino. Ao ensinar, assim como ao avaliar, é fundamental ter, por meta, uma planificação da qual constam os fins almejados para o desencadeamento de ações intencionais.

Considerando que para avaliar, formativamente, Fernandes $(2009$, p. 59) afirma que é preciso "[...] definir prévia e claramente os propósitos e a natureza do processo de ensino e avaliação [...]", evidencia-se a necessidade de estabelecimento de objetivos a serem perseguidos e progressivamente edificados nas ações de ensino, como também constantemente verificados pela proposição de diferentes atividades avaliativas.

Ao diagnosticar as dificuldades de aprendizagem e os erros manifestos nas atividades realizadas, pelo confronto entre o almejado e o alcançado, o interesse desses professores não é a atribuição de graus ou menções, mas obter subsídios de que os ajudem a compreender os limites e as possibilidades dos alunos, assim como lhes facultem planificar ações pertinentes e adequadas às superações necessárias e viáveis no momento seguinte. Em concordância com Hoffmann (2004, p. 26), o interesse não é

[...] reunir informações para justificar uma etapa de aprendizagem, mas acompanhar com atenção e seriedade todas as etapas vividas pelo estudante para ajustar, no decorrer de todo o processo, estratégias pedagógicas. Visa, portanto, ao encaminhamento de alternativas de solução e melhoria do objeto avaliado.

$\mathrm{Na}$ avaliação formativa, os objetivos orientam os caminhos que serão delineados no processo de avaliação da aprendizagem. A especificação dos objetivos é uma importante tarefa docente, pois permitirá proceder a balanços permanentes entre as metas estabelecidas e as realizações efetivadas. Ou seja, "[...] pode-se dizer que em torno dos objetivos gravita todo o trabalho do professor. Definir objetivos significa definir a aprendizagem do aluno, bem como tudo que poderá ser feito para torná-la [...] 


\section{SEMINÁRIO DE PESQUISA EM CIÊNCIAS HUMANAS - SEPECH \\ Humanidades, Estado e desafios didático-científicos \\ Londrina, 27 a 29 de julho de 2016}

significativa." (PELISSONI, 2009, p. 132).

Segundo alguns autores (MARTINS, 2006; LUCKESI, 2003, 2005, 2011; PELISSONI, 2009; SALINAS, 2004, VILLAS BOAS, 2011, dentre outros), os objetivos direcionam na escolha da estratégia de ensino, na composição dos instrumentos avaliativos, na reorientação da aprendizagem, bem como na revisão da ação pedagógica pelo próprio professor. De acordo com Pelissoni $(2009$, p. 131), “[...] a definição clara dos objetivos prepara o processo de avaliação da aprendizagem."

No momento de avaliar, como são numerosos e diversos os objetivos, também podem ser diversos e numerosos os instrumentos avaliativos utilizados para conhecer a aprendizagem dos estudantes. Todavia, ao ampliar o número e diversificar o tipo de instrumentos avaliativos, o intuito não é aumentar as formas de controle, pois, consoante Esteban $(2008$, p. 32), para avaliar "é preciso produzir instrumentos e procedimentos que nos ajudem a dar voz e visibilidade ao que é silenciado e apagado. Com muito cuidado, porque a intenção não é melhor controlar e classificar, mas sim melhor compreender e interagir."

A diversificação do instrumental avaliativo é fundamental a realização de uma avaliação mais formativa. Não basta e não é suficiente, porém, é relevante na tentativa de assegurar um pouco mais de justiça ao processo por asseverar um pouco mais, o respeito às diferenças, até porque, conforme Teixeira e Nunes (2008, p. 167),

[...] por mais que uma escola se anuncie como tradicional, nos dias atuais, não existe mais a possibilidade de se avaliar o aluno apenas pela nota da prova. Diversos outros fatores devem ser levados em consideração. Conhecer técnicas facilita as estratégias de atender às demandas escolares.

$\mathrm{Na}$ efetivação da avaliação formativa, os instrumentos avaliativos serão selecionados dentre aqueles que melhor atendam ao desvelamento dos objetivos de ensino propostos e às suas repercussões em termos de aprendizagem. A coleta de informações - diversas e relevantes - permitirá a determinação da distância ainda existente entre o real (a aprendizagem conquistada) e o ideal (a aprendizagem descrita sob o formato de objetivos). Contudo, tais informações configurar-se-ão e serão um ponto de referência para outras ações didáticas, somente se revelarem

No momento da interpretação e da análise das informações colhidas, requer que se compreendam os conhecimentos que o estudante já traz consigo, bem como o caminho percorrido por ele para aprender. Demanda compreender as razões subjacentes aos erros cometidos, e essas podem ser numerosas e variadas, assim como são distintos os estudantes presentes em sala.

Para Hadji (2001, p. 98, destaque do autor), "uma avaliação formativa deveria possibilitar a 'compreensão' da situação do aluno, de modo a imaginar ações corretivas eficazes. Essa compreensão é possível pela dupla operação de coleta de informações e de análise de resultados." Avaliar para identificar problemas e pensar a respeito deles é fundamental quando se desencadeia um processo avaliativo que pretenda ser formativo. De acordo com Ribeiro (2011, p. 52), “[...] a análise das informações focaliza-se na reflexão, na investigação acerca dos erros e das dificuldades apresentados pelos estudantes, visando a fundamentar ações favoráveis à superação dos problemas encontrados [...]”. Dessa forma, analisando-se os resultados, torna-se possível 


\section{SEMINÁRIO DE PESQUISA EM CIÊNCIAS HUMANAS - SEPECH \\ Humanidades, Estado e desafios didático-científicos \\ Londrina, 27 a 29 de julho de 2016}

encaminhar o ensino pretendendo a melhoria da aprendizagem.

A identificação dos objetivos não alcançados - em decorrência da identificação dos erros cometidos - gera, ou precisaria gerar, um outro compromisso por parte dos professores: compreender a razão de ocorrência das falhas para poder conceber ações de intervenção que primem pela superação, que invistam na aprendizagem. Todavia, é preciso transformar o planificado em ação, o que envolve suplantar o erro, pela promoção de feedbacks que intentam "[...] alcançar os alunos que não aprendem, por fornecer subsídios para que ultrapassem os seus limites e adquiriam os conhecimentos tão valorizados socialmente." (TEIXEIRA; NUNES, 2008, p. 72).

A ciência dos problemas de aprendizagem possibilita a regulação do ensino pela promoção de feedbacks que propiciem orientações, enquanto abrem possibilidades para a confrontação de respostas e soluções para a permuta de informações entre os pares, "[...] quer reconhecendo os seus progressos e sucessos, quer ajudando a ultrapassar os seus pontos fracos." (FERNANDES, 2006, p. 96).

O feedback precisa orientar o estudante nas medidas a serem por ele assumidas diante dos próprios erros, a fim de superá-los. Reconhecer o potencial construtivo do feedback - utilizando-o como um elo entre professor e estudante, no intuito de enfrentar os obstáculos encontrados para aprender - demanda, além do estabelecimento de diálogo, o oferecimento pelo professor, de informações que possam ser utilizadas pelo estudante de modo a garantir a aprendizagem (BLACK, 1995; ESTEBAN, 2001, 2002, 2003, 2006, 2008; FERNANDES, 2006; HADJI, 2001; PERRENOUD, 1999; TEIXEIRA; NUNES, 2008).

A variabilidade didática é aspecto essencial à consecução de avaliação formativa. Ela rompe com o modelo transmissão, recepção, retenção, reprodução e revela disposição, por parte do professor, para atuar com mais flexibilidade, procedendo à adaptações e ajustes que se configuram necessários. Por considerar os problemas de aprendizagem identificados e as razões de sua ocorrência, Hadji (2001, p. 21) assegura que o reconhecimento externo da ocorrência, ou não, de uma avaliação formativa é "[...] o aumento da variabilidade didática. Uma avaliação que não é seguida por uma modificação das práticas do professor tem poucas chances de ser formativa!" Agir formativamente abarca proporcionar a variabilidade didática, fazendo o erro, que estava oculto na avaliação classificatória, transformar-se em protagonista do processo de ensino e aprendizagem.

Assumir o risco de agir de maneira diferenciada daquela que foram ensinados quando estavam em formação, para se assumirem como professores investigadores, é preciso dispor de informações acerca das aprendizagens edificadas e daquelas em curso, propondo caminhos para o estudante aprender além de desencadear alternativas pedagógicas pertinentes à promoção de superações.

Oferecer ajuda aqueles com dificuldades de aprendizagem é essencial no processo de avaliação de aprendizagem. Para tanto, os erros precisam ser vistos pelos professores com outros olhos, abstendo-se de julgamentos e qualificações, propiciando a análise e compreensão das dificuldades. Reconhecendo a multiplicidade de pensamentos, reações, sentimentos, conhecimentos prévios, habilidades, formas de perceber o mundo e a ele reagir.

Olhar de maneira compreensiva para o cenário e pessoas que nele estão, é fundamental retirar a máscara preconceituosa de pesquisador e respeitar os professores participantes, entendendo que seus pensamentos e ações revelam aprendizagens por eles 


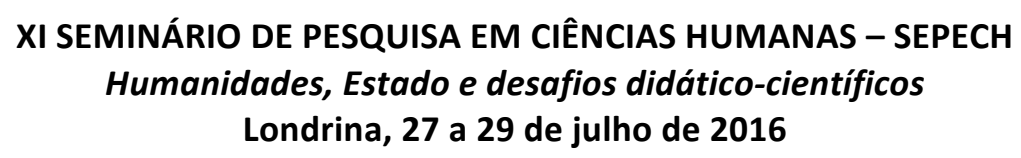

edificadas ao longo de suas vivências escolares. Todavia, eles desejam mudar, apenas não sabem como e não lhes são ofertadas possibilidades de refletirem e aprenderem.

Compreender que os professores, assim como os estudantes, têm o seu próprio tempo, o seu próprio ritmo, e que deles não podem ser cobradas respostas-padrão, mas precisa ser-lhes ofertadas condições para edificarem a construção de seus conceitos com autonomia, teoricamente e empiricamente embasada.

\section{REFERÊNCIAS}

ÁLVAREZ MÉNDEZ, Juan Manuel. Avaliar para conhecer: examinar para excluir Tradução de Magda Schwartzhaupt Chaves. Porto Alegre: Artmed, 2002. Tradução de: Evaluar para conocer, examinara para excluir.

BLACK, Paul. Can teachers use assessment to improve learning? British Journal of Curriculum \& Assessment. v. 5, n. 2, p. 7-11, 1995. Artigo traduzido e publicado com a autorização do autor e da Editora Hodder and Stoughton. Tradução de Fernando Zan Vieira. Disponível em: $<\underline{\text { http://www.revistas2.uepg.br/index.php/praxiseducativa/article/view/717/657> }}$ Acesso em: 14 jul. 2012.

ESTEBAN, Maria Teresa. Avaliar: ato tecido pelas imprecisões do cotidiano. s/d. Disponível em: $<$ http://www.anped.org.br/reunioes/23/textos/0611t.pdf $>$. Acesso em: 15 abr. 2016. 1992.

Repensando o fracasso escolar. Cadernos Cedes, Campinas, n. 28, p.7586,

O que sabe quem erra? Reflexões sobre avaliação e fracasso escolar. Rio de Janeiro: DP\&A, 2001.

- Avaliação no processo ensino/aprendizagem: os desafios postos pelas múltiplas faces do cotidiano. Revista Brasileira de Educação. n.19, Jan./Fev./Mar./Abr. 2002.

Avaliação: uma prática em busca de novos sentidos. 5. ed. Rio de Janeiro: $\overline{\mathrm{DP} \& \mathrm{~A}}, 2003$.

Sala de Aula - dos lugares fixos aos entrelugares fluidos. Revista Portuguesa de Educação, Minho, Portugal, v. 19, n.2, p. 7-20, 2006. Disponível em: $<$ http://redalyc.uaemex.mx/pdf/374/37419202.pdf >. Acesso em: 20 jul. 2011.

. (Org.). Escola, currículo e avaliação. 3. ed. São Paulo: Cortez, 2008. 5 v.

FERNANDES, Domingos. Para uma teoria da avaliação formativa. Revista Portuguesa de Educação, v. 19, n. 2, p. 21-50, 2006. Disponível em: 


\section{SEMINÁRIO DE PESQUISA EM CIÊNCIAS HUMANAS - SEPECH \\ Humanidades, Estado e desafios didático-científicos \\ Londrina, 27 a 29 de julho de 2016}

$<$ http://www.scielo.oces.mctes.pt/scielo.php?script=sci_arttext\&pid=S08719187200600 0200003\&lng=pt\&nrm=iso $>$. Acesso em: 21 abr. 2012.

HADJI, Charles. Avaliação desmistificada. Porto Alegre: ArtMed, 2001.

HOFFMANN, Jussara. Avaliar para promover: As setas do caminho. Porto Alegre: Mediação, 2001.

LOPES, Sérgio Luis. A (anti) Pedagogia da nota na escola. 2006. 219 f. Dissertação (Mestrado em Ciências Sociais) - Universidade Federal do Rio Grande do Norte, Natal, 2006. Disponível em:

$<$ http://bdtd.bczm.ufrn.br/tedesimplificado/tde_arquivos/7/TDE-2008-03-

26T045002Z1143/Publico/SergioLL.pdf $>$. Acesso em: 23 jul. 2011.

LUCKESI, Cipriano Carlos. Avaliação da aprendizagem escolar: sendas percorridas. 1992. 235 f. Tese (Doutorado em Filosofia) - Universidade Católica de São Paulo, São Paulo, 1992. 1v.

. O que é mesmo o ato de avaliar a aprendizagem? Pátio. Porto alegre:

ARTMED. Ano 3, n. 12 fev./abr. $2000 . \quad$ P. 2. https://www.nescon.medicina.ufmg.br/biblioteca/imagem/2511.pdf

Avaliação da aprendizagem na escola: reelaborando conceitos e recriando a prática. Salvador: Malabares Comunicações e Eventos, 2003.

. A avaliação da aprendizagem escolar: estudos e proposições. 17. ed. São Paulo: Cortez, 2005.

Avaliação da aprendizagem: componente do ato pedagógico. 1. ed. São Paulo: Cortez, 2011.

PELISSONI, Adriane M. Soares. Objetivos educacionais e avaliação da aprendizagem. Anuário da Produção acadêmica docente, v. 3, n. 5, p.129-139, 2009. Disponível em: $<$ http://sare.unianhanguera.edu.br/index.php/anudo/article/view/1585/745 $>$. Acesso em: 12 abr. 2012.

PERRENOUD, Philippe. Avaliação: da excelência à regulação das aprendizagens. Entre duas lógicas. Tradução de Patrícia C. Ramos. Porto Alegre: Artmed, 1999. Tradução de: L'évaluation deséleves: de La fabrication de l' excellence à La régulation dês apprentissages. Entre deux logiques.

RIBEIRO, Elizabete Aparecida Garcia. Avaliação formativa em foco: concepção e características no discurso discente. 2011. 137 f. Dissertação (Mestrado em Educação) Universidade Estadual de Londrina, Londrina. 


\section{SEMINÁRIO DE PESQUISA EM CIÊNCIAS HUMANAS - SEPECH \\ Humanidades, Estado e desafios didático-científicos \\ Londrina, 27 a 29 de julho de 2016}

SANTOS GUERRA, Miguel Ángel. Uma flecha no alvo: a avaliação como aprendizagem. Tradução de Luciana Moreira Pudenzi. São Paulo: Edições Loyola, 2007. Tradução de: Una flecha en la diana: La evaluación como aprendizaje.

TEIXEIRA, Josele; NUNES, Liliane. Avaliação escolar: da teoria à prática. Rio de Janeiro: Wak, 2008.

VILLAS BOAS, Maria Benigna de Freitas. Compreendendo a avaliação formativa. In: VILLAS BOAS, Maria Benigna de Freitas (Org.). Avaliação formativa: práticas inovadoras. Campinas: Papirus, 2011. Coleção Magistério: Formação e trabalho pedagógico. p. 13-42.

ZANATTO, Rinaldo. Perfil motivacional dos alunos de Arquitetua: um estudo exploratório. 2007. 132 f. Dissertação (Mestrado em Educação) - Universidade Estadual de Londrina, Londrina. Disponível em: $<$ http://www.uel.br/pos/mestredu/images/stories/downloads/dissertacoes/2007/2007 \%20-\%20ZANATTO,\%20Rinaldo.pdf > . Acesso em: 27 jul. 2010. 